\title{
Untargeted Metabolomics Approach in Halophiles: Understanding the Biodeterioration Process of Building Materials
}

\section{OPEN ACCESS}

Edited by:

Michael Sauer

University of Natural Resources and

Life Sciences, Vienna, Austria

Reviewed by:

Karin Ortmayr,

ETH Zurich, Switzerland

Tim Causon,

University of Natural Resources and

Life Sciences, Vienna, Austria Julijana Ivanisevic,

University of Lausanne, Switzerland

*Correspondence:

Justyna Adamiak

justyna.adamiak@dokt.p.lodz.pl

Specialty section:

This article was submitted to Microbial Physiology and Metabolism,

a section of the journal

Frontiers in Microbiology

Received: 07 August 2017 Accepted: 24 November 2017 Published: 11 December 2017

Citation:

Adamiak J, Bonifay V, Otlewska A Sunner JA, Beech IB, Stryszewska T, Kańka S, Oracz J, Żyżelewicz D and

Gutarowska B (2017) Untargeted

Metabolomics Approach in

Halophiles: Understanding the Biodeterioration Process of Building Materials. Front. Microbiol. 8:2448.

doi: $10.3389 /$ fmicb.2017.02448
Justyna Adamiak ${ }^{*}$, Vincent Bonifay ${ }^{2}$, Anna Otlewska ${ }^{1}$, Jan A. Sunner ${ }^{2}$, Iwona B. Beech ${ }^{3}$, Teresa Stryszewska ${ }^{4}$, Stanisław Kańka ${ }^{4}$, Joanna Oracz ${ }^{5}$, Dorota Żyżelewicz ${ }^{5}$ and Beata Gutarowska ${ }^{1}$

${ }^{1}$ Institute of Fermentation Technology and Microbiology, Faculty of Biotechnology and Food Sciences, Lodz University of Technology, Lodz, Poland, ${ }^{2}$ Department of Microbiology and Plant Biology, University of OKlahoma, Norman, OK, United States, ${ }^{3}$ Center of Biofilm Engineering, Department of Chemical and Biochemical Engineering, Montana State University, Bozeman, MT, United States, ${ }^{4}$ Institute of Building Materials and Structures, Faculty of Civil Engineering, Cracow University of Technology, Cracow, Poland, ${ }^{5}$ Institute of Food Technology and Analysis, Faculty of Biotechnology and Food Sciences, Lodz University of Technology, Lodz, Poland

The aim of the study was to explore the halophile metabolome in building materials using untargeted metabolomics which allows for broad metabolome coverage. For this reason, we used high-performance liquid chromatography interfaced to high-resolution mass spectrometry (HPLC/HRMS). As an alternative to standard microscopy techniques, we introduced pioneering Coherent Anti-stokes Raman Scattering Microscopy (CARS) to non-invasively visualize microbial cells. Brick samples saturated with salt solution $\left(\mathrm{KCl}, \mathrm{NaCl}\right.$ (two salinity levels), $\left.\mathrm{MgSO}_{4}, \mathrm{Mg}\left(\mathrm{NO}_{3}\right)_{2}\right)$, were inoculated with the mixture of preselected halophilic microorganisms, i.e., bacteria: Halobacillus styriensis, Halobacillus naozhouensis, Halobacillus hunanensis, Staphylococcus succinus, Marinococcus halophilus, Virgibacillus halodenitryficans, and yeast: Sterigmatomyces halophilus and stored at $28^{\circ} \mathrm{C}$ and $80 \%$ relative humidity for a year. Metabolites were extracted directly from the brick samples and measured via HPLC/HRMS in both positive and negative ion modes. Overall, untargeted metabolomics allowed for discovering the interactions of halophilic microorganisms with buildings materials which together with CARS microscopy enabled us to elucidate the biodeterioration process caused by halophiles. We observed that halophile metabolome was differently affected by different salt solutions. Furthermore, we found indications for haloadaptive strategies and degradation of brick samples due to microbial pigment production as a salt stress response. Finally, we detected changes in lipid content related to changes in the structure of phospholipid bilayers and membrane fluidity.

Keywords: halophilic microorganisms, metabolomics, HPLC/HRMS, CARS microscopy, haloadaptation, biodeterioration, brick

\section{INTRODUCTION}

The durability of building materials, including those of historical value, is influenced by numerous physical, chemical, and biological factors. Among them, salt crystallization, which forms as a result of salt migration with capillary water and subsequent drying out and precipitation, poses a serious threat to the materials' structure (Stryszewska, 2014). Moreover, salt-attacked 
monuments constitute a suitable habitat for halophilic microorganisms (Piñar et al., 2014; Adamiak et al., 2015; Otlewska et al., 2017) as these can easily adapt to salty microniches available on a building's surface, thus contributing to its structural destabilization (Saiz-Jimenez and Laiz, 2000; Piñar et al., 2009; Adamiak et al., 2015, 2016).

Microbial metabolomics has proved to be an emerging field for microorganism identification, mutant screening, and functional gene research, metabolic pathway identification, and microbial engineering. Over the last two decades it has provided new insights on the activities of microbes in response to environmental conditions (Xu et al., 2014; Villas-Boas, 2016). Recently, several outstanding papers on microbial metabolomics have been published (Rochfort, 2005; Mashego et al., 2007; van der Werf et al., 2007; Tang, 2011; Baidoo et al., 2012; Xu et al., 2014; Barkal et al., 2015). To our knowledge, there are only a limited number of reports on biodeterioration and biocorrosion processes (Lenhart et al., 2014; Brauer et al., 2015; Gutarowska et al., 2015; Bonifay et al., 2017; Szulc et al., 2017), and none of them has focused on halophilic microorganisms.

Biodeterioration of building materials due to active growth of microorganisms is another area where microbial metabolomics has much to offer. For example, Gutarowska et al. (2015) used ultra-high performance liquid chromatography coupled to high-resolution mass spectrometry (UPLC/HRMS) to investigate activated pathways of microbial communities inhabiting wood and brick collected from historical objects. Szulc et al. (2017) compared the metabolite profiles of molds on cartongypsum board using a high-resolution surface-assisted laser desorption/ionization time-of-flight mass spectrometry based on a gold nanoparticle-enhanced target (AuNPET SALDI-ToFMS) imaging method. Growing awareness of biodeterioration of building materials and halophiles contributing to this phenomenon (Rölleke et al., 1998; Heyrman et al., 1999; Laiz et al., 2000, 2009; Piñar et al., 2001, 2014; Ripka et al., 2006; Ettenauer et al., 2014) has highlighted gaps in our understanding of the metabolic pathways that characterize halophilic communities colonizing historical buildings. At present, there are no studies providing an in-depth metabolomic assessment of halophiles-induced biodeterioration.

A well-known phenomenon found on wall surfaces is the formation of salt efflorescence, which mimics the extreme salty conditions favoring the proliferation of halophiles (Sterflinger and Piñar, 2013). The ability of halophilic microorganisms to cope with osmotic stress in hypersaline environments is an important adaptation. Two different strategies for coping with osmotic stress have been reported. One involves the accumulation of inorganic ions (mostly $\mathrm{K}^{+}$and $\mathrm{Cl}^{-}$rather than $\mathrm{Na}^{+}$) and is known as the "salt-in-cytoplasm" strategy. The other, known as the "compatible solute" strategy employs the uptake or synthesis of organic molecules, namely sugars and polyols or $\alpha$ - and $\beta$-amino acids with their derivatives (Madigan and Oren, 1999; Xiang et al., 2008; Averhoff and Müller, 2010). When studying the interactions of halophilic microorganisms with building materials, we should take into consideration not only their ability to survive in a high-salt environment (haloadaptation), but also their contribution to the degradation of building materials. A wide range of carotenoid pigments, such as $\beta$-carotene, $\alpha$-bacterioruberin and derivatives, and salinixanthin is produced by halophilic microorganisms (Oren, 2002). They are the major cause of typical rosy stains, significantly influencing the visual appearance of building material (Sterflinger and Piñar, 2013). Organic acids also play an important role, because they contribute to cracking and detachment of building materials (Gutarowska and Czyzowska, 2009). Halophilic microorganisms isolated from salterns, brines, sediments, and soil were shown to produce organic acids; e.g., gluconic acid, 2-ketogluconic, citric acid, formic acid, succinic acid, fumaric acid, and acetic acid (Tomlinson and Hochstein, 1972; Vreeland et al., 1998; Yadav et al., 2015); however, this ability was not confirmed for isolates from a building environment.

When elucidating the biodeterioration caused by halophilic microorganisms, it can be helpful to utilize microscopic methods. However, rapid detection of microbes in their natural environment (Hong et al., 2016) is still a challenge. Here, we report the use of coherent anti-Stokes Raman scattering (CARS) for in situ detection of a single living cell. This state-of-the-art technology offers a non-invasive, label-free, and direct way to image biological samples with chemical sensitivity (Cheng et al., 2002; Cheng and Xie, 2004; Rodriguez et al., 2006). It relies on the abundance of $\mathrm{CH}_{2}$ groups in lipids and the distinctive $\mathrm{CH}_{2}$ stretch vibration frequency at $2,840 \mathrm{~cm}^{-1}$ (Folick et al., 2011), thus enabling detection of a single bacterium. CARS requires the input of two laser pulses, a pump-probe beam and a Stokes beam, which interact with the specimen to generate an anti-Stokes field. When the frequency difference between the pump and the Stokes pulses matches the frequency of a certain molecular vibration, a strong signal is generated, allowing molecule-specific imaging (Zhang et al., 2015; Hong et al., 2016). Visualizing lipid structures in live cells may therefore represent an alternative to standard procedures employed in biodeterioration studies.

The present work focused on untargeted metabolomics using high-performance liquid chromatography coupled to high-resolution mass spectrometry (HPLC/HRMS) to explore the halophile metabolome. Mass spectrometry is known to be the most sensitive and selective technique among many platforms. This work demonstrates that a combination of what might be termed "community metabolomics" and stateof-the-art CARS microscopy has an enormous potential for the comprehensive characterization of biodeterioration on saltattacked buildings. Therefore, the aim of the research was to: (1) identify groups of metabolites produced by mixed cultures of halophilic microorganisms that may be potentially responsible for degradation of brick; (2) reveal the pattern of metabolic responses of halophilic microorganisms to severe saline conditions; and (3) visualize live cells of halophilic microorganisms with CARS.

\section{EXPERIMENTAL PROCEDURES}

\section{Brick Samples Preparation Exposure to Salty Corrosive Environment}

Samples $(n=9)$ of dimensions $65 \times 65 \times 65 \mathrm{~mm}$ were cut out of burnt ceramic brick, which physical properties, chemical and phase composition showed in Supplementary Materials 1 


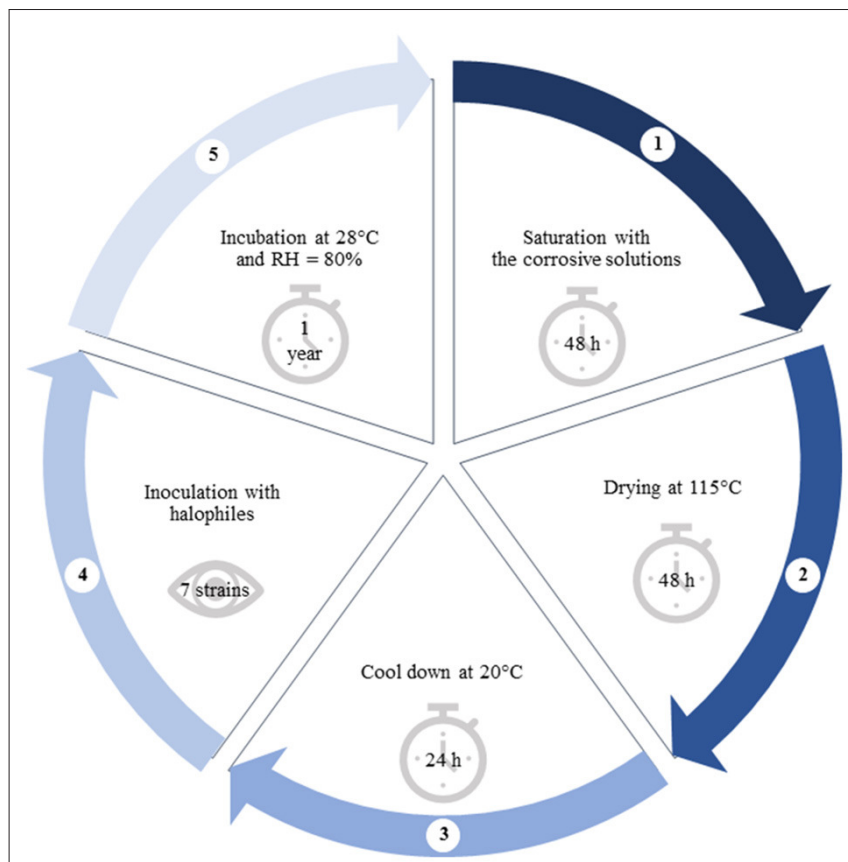

FIGURE 1 | Diagram showing the following steps of brick sample preparation.

were determined according to (Stryszewska, 2014). Samples in duplicates were exposed to salty corrosive environment periodically (Stryszewska, 2014). Over 2 days each sample was immersed up to half of its height in the corrosive solution, i.e., potassium chloride (sample I), sodium chloride (II), magnesium sulfate (III) and magnesium nitrate (IV) of $50 \mathrm{~g} / \mathrm{dm}^{3}$. As a result of capillary action, the samples were entirely saturated with salty corrosive solutions. For the next 2 days the samples were dried at $115^{\circ} \mathrm{C}$ and then cooled down at $20^{\circ} \mathrm{C}$. A single cycle of exposure to the corrosive environment took 5 days in total (Figure 1). In this paper the authors present results after the full 1 cycle of exposure to all corrosive salt solutions (samples I_1 $\div$ IV_1) and the full 3 cycles of the exposure only to sodium chloride for comparison (sample II_3).

\section{Inoculation with Halophilic Microorganisms}

One of the two samples that were saturated with the same salt solution was inoculated with the mixture of 7 strains of halophilic microorganisms at regular intervals throughout a year (Figure 1, Table 1) (Inoculated samples: I_1, II_1, III_1, IV_1, II_3). They were isolated from deteriorated historic buildings with visible symptoms of dampness and salt efflorescence and characterized in our previous studies (Adamiak et al., 2016; Otlewska et al., 2017). The second sample was served as a control (Uninoculated samples: I, II, III, IV). It was kept in the same conditions; however it was not inoculated with mixed cultures of halophilic microorganisms (samples I $\div$ IV). The bacterial cultures were activated on TSB medium with both $10 \% \mathrm{NaCl}$ $(\mathrm{w} / \mathrm{v})$ and $2 \% \mathrm{MgSO}_{4} \times 7 \mathrm{H}_{2} \mathrm{O}(\mathrm{w} / \mathrm{v})$ and incubated aerobically at $30^{\circ} \mathrm{C}$ for 5 days. The cultures were centrifuged $(6,000 \times$ g, $20 \mathrm{~min}$ ), and the biomass was suspended in M0 medium
$\left[\left(\mathrm{NH}_{4}\right)_{2} \mathrm{SO}_{4} 0.075 \%, \mathrm{~K}_{2} \mathrm{HPO}_{4} 0.025 \%, \mathrm{MgSO}_{4} \times 7 \mathrm{H}_{2} \mathrm{O} 0.125 \%\right.$, yeast extract $0.125 \%$, glucose $0.5 \%, \mathrm{pH} 6.0$ ]. To obtain mixed cultures, bacterial strains were combined in equal volumes. The density of the suspension was adjusted to $10^{8} \mathrm{CFU} / \mathrm{ml}$. The suspension was applied on the surface of brick samples. In order to promote growth and to elucidate biodeterioration caused by halophilic microorganisms, all samples were stored at $28^{\circ} \mathrm{C}$ and exposed to high humidity $(\mathrm{RH}=80 \%)$ for a year. Untreated brick-unsalted and uninoculated, (The Fired Brick Production "Konstantynów" in Sanniki, Poland) was served as a reference sample (Sample K).

\section{Metabolomic Protocol Extraction Procedures}

The field sample of $0.5 \mathrm{~g}$ of ground brick, was acidified to $\mathrm{pH} 2$ with $3.0 \mathrm{ml}$ of $4 \mathrm{~N} \mathrm{HCl}$ (ACS grade, EMD Millipore) and sonicated in a water bath for $30 \mathrm{~min}$. The mixtures were extracted into $3 \mathrm{ml}$ ethyl acetate (HPLC grade, Sigma Aldrich), 2 times each and centrifuged at $1 \times \mathrm{g}$ for $5 \mathrm{~min}$. The derived extracts were evaporated to dryness under ultrapure nitrogen gas (Grade 5.0) and dissolved in $100 \mu \mathrm{l}$ of isopropanol (HPLC grade, Sigma Aldrich). The injection volume was $5 \mu \mathrm{l}$. Three biological replicates of each sample were analyzed (biological replicate in this study refers to an individual of the same group in the experiment), with $p$-value of 0.01 for abundance comparisons between the sets of triplicates.

\section{HPLC/HRMS Analysis}

The metabolite extracts were analyzed on an Agilent 1290 Infinity HPLC coupled to an Agilent 6545 Ultra High Definition Q-TOF mass spectrometer. Samples were measured in both a positive and a negative ion mode. A SeQuant ${ }^{\circledR}$ ZIC ${ }^{\circledR}$-HILIC column (particle diameter $5 \mu \mathrm{m}, 150 \times 4.6 \mathrm{~mm}$, The Nest Group, Inc., Mass., USA) was used for LC separation of metabolites for HPLC/HRMS analysis in a positive ion mode with a flow rate $0.3 \mathrm{ml} / \mathrm{min}$. The mobile phase was composed of $\mathrm{A}=\mathrm{LCMS}$ grade water (EMD Millipore) with $0.1 \%$ formic acid and $\mathrm{B}=$ LCMS grade acetonitrile (EMD Millipore) with $0.1 \%$ formic acid (HPLC grade, Sigma Aldrich). A linear gradient elution from 80 to $20 \%$ acetonitrile was applied for $30 \mathrm{~min}$, followed by $5 \%$ acetonitrile for the next $8 \mathrm{~min}$. MS parameters were as follows: ion-source gas temperature $350^{\circ} \mathrm{C}$, capillary voltage $3,500 \mathrm{~V}$, fragmentor voltage $160 \mathrm{~V}, \mathrm{~m} / \mathrm{z}$ range $50-1,100$, data acquisition rate $4 \mathrm{GHz}, 1$ spectrum recorded per second. For separation in a negative ion mode, an Acquity UPLC ${ }^{\circledR} \mathrm{BEH}$ C18 SB column (particle diameter $1.8 \mu \mathrm{m}, 100 \times 2.1 \mathrm{~mm}$, Waters, Ireland) was used with a flow rate $0.4 \mathrm{ml} / \mathrm{min}$. For the first $35 \mathrm{~min}$, a linear gradient from 23.5 to $95.5 \%$ acetonitrile (LCMS grade, EMD Millipore) was used, followed by $5 \mathrm{~min}$ at $95.5 \%$.

\section{Data Analysis}

Raw data was analyzed using IDEOM v. 19 workflow (Creek et al., 2012) which enables processing of metabolomics data to annotated and hyperlinked metabolite lists. LC-MS files were processed in the R environment (https://www.r-project.org) ( $\mathrm{R}$, 2008), using XCMS centWave (Smith et al., 2006; Tautenhahn 
TABLE 1 | The list of preselected halophilic microorganisms combined in order to inoculate the brick samples.

\begin{tabular}{|c|c|c|c|c|}
\hline Strains & $\begin{array}{l}\text { GenBank accession } \\
\text { number }\end{array}$ & Isolation area & $\begin{array}{l}\text { Inhabited historic } \\
\text { buildings* }\end{array}$ & References \\
\hline Halobacillus styriensis & KU550580.1 & \multirow{2}{*}{ Brick $^{a}$} & Castles & Piñar et al., 2001; Ripka et al., 2006 \\
\hline Halobacillus naozhouensis & KU550581.1 & & Castles & Piñar et al., 2001; Ripka et al., 2006 \\
\hline Staphylococcus succinus & KU550582.1 & \multirow{2}{*}{ Brick $^{b}$} & Wall paintings catacombs & Ettenauer et al., 2014; Piñar et al., 2014 \\
\hline Halobacillus hunanensis & KU550583.1 & & Catacombs & Piñar et al., 2014 \\
\hline Marinococcus halophilus & KU550584.1 & \multirow{2}{*}{ Brick $^{C}$} & Wall paintings & Ettenauer et al., 2014 \\
\hline Sterigmatomyces halophilus & KU550579.1 & & nd & - \\
\hline Virgibacillus halodenitrificans & KU550585.1 & Plaster with paint coatings ${ }^{d}$ & Catacombs walls of well & Xiang et al., 2008; Piñar et al., 2014 \\
\hline
\end{tabular}

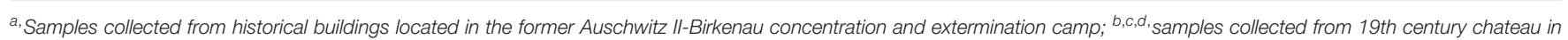
Łódz. *Known from literature; nd, not detected in previous studies; - lack of data.

et al., 2008) and mzmatch. R tools (http://mzmatch.sourceforge. net/index.php) (Scheltema et al., 2011). Raw peaks were extracted by XCMS Centwave, while mzmatch.R allowed peak matching, noise filtering, gap-filling, annotation of related peaks and storage of the data in peakML files. Parameter settings were as follows: centWave for feature detection, $\Delta \mathrm{m} / \mathrm{z}=10 \mathrm{ppm}$; minimum peak width $=15 \mathrm{~s}$ and maximum peak width $=100 \mathrm{~s}$ and parameters for chromatogram alignment, including a retention time window of $0.5 \mathrm{~min}$ and mass error window of $5 \mathrm{ppm}$. The result of the peak alignment is a list of compounds with associated mass and retention time.

Metabolite identification was achieved by matching the mass and retention time of observed peaks to metabolites in the database. i.e., KEGG, Kyoto Encyclopedia of Gens and Genomes, (Kanehisa et al., 2014), Metacyc (Caspi et al., 2014), Lipidmaps (Fahy et al., 2009) and HMDB (Wishart et al., 2013), with mass tolerance of $4 \mathrm{ppm}$. Retention times for authentic standards, and a retention time prediction model, were included for ZICHILIC chromatography data (Creek et al., 2011). The retention time calculator uses physic-chemical properties to predict retention times based on a multiple linear regression model with 120 authentic standards. (QSPR approach). To calibrate the retention time predictor 33 metabolite standards were used (Supplementary Materials 2). In our study, metabolites matching 5 of the standards were observed (written in bold; Supplementary Materials 2). The maximum difference between calculated and observed RT for authentic standards was $5 \%$, whereas for other metabolites it was set to $45 \%$ (when experimentally observed retention time was more than $45 \%$ off from that calculated by the model, putative metabolites were rejected). With the use of retention time calculator, an identification level of 2 can be claimed (putatively annotated compounds; Sumner et al., 2007).

Multi group analysis, interpretation and visualization of statistically significant results was performed with MetaboAnalyst $3.0 \quad$ (http://www.metaboanalyst.ca) and XCMS Online (http://xcmsonline.scripps.edu), which enabled the evaluation of the metabolite variation across different experimental groups and provided the univariate analysis of variance (one-way ANOVA) as a parametric test option. To display the metabolites identified in the context of metabolic pathways in which they occur, Pathos (http://motif.gla.ac.uk/Pathos/) and KEGG (http://www.genome.jp/kegg/pathway.html) were utilized.

\section{$\beta$-carotene Identification}

$\beta$-carotene was analyzed with ultra-high-performance liquid chromatography-diode array detector-tandem mass spectrometry (UHPLC-DAD-ESI-MS). Chromatographic analyses were performed using UHPLC+ Dionex UltiMate 3000 system (Thermo Fisher Scientific Inc., Waltham, Massachusetts, USA), coupled to both a diode array detector with multiplewavelength (Thermo Fisher Scientific Inc., USA), and Q-Exactive Orbitrap $^{\mathrm{TM}}$ mass spectrometer (Thermo Scientific, USA). Accucore C30 column (particle diameter $2.6 \mu \mathrm{m}, 100 \times$ $3.0 \mathrm{~mm}$, Thermo Fisher Scientific Inc., USA) was used. The column temperature was maintained at $35^{\circ} \mathrm{C}$. The gradient elution was carried out using methanol (HPLC grade, J. T. Baker Chemicals) as solvent system A, methyl tert-butyl ether (HPLC grade, J. T. Baker Chemicals) as solvent system B and ultrapure water (EMD Millipore) as solvent system C, and applied as follows: $2 \% \mathrm{~B}$ and $2 \% \mathrm{C}$ at $0-1 \mathrm{~min}, 80 \% \mathrm{~B}$ and $2 \% \mathrm{C}$ at $35 \mathrm{~min}, 80-2 \% \mathrm{~B}$ and $2 \% \mathrm{C}$, over $35.0-38.0 \mathrm{~min}$, and held at $2 \% \mathrm{~B}$ and $2 \% \mathrm{C}$ until $50.0 \mathrm{~min}$. The injection volume was $5 \mu \mathrm{L}$ and the flow rate used was $0.4 \mathrm{ml} / \mathrm{min}$. The chromatograms were recorded at processed at $450 \mathrm{~nm}$. The mass spectrometer conditions were as follows: capillary temperature $350^{\circ} \mathrm{C}$, heater gas temperature $250^{\circ} \mathrm{C}$, electrospray capillary voltage $3.5 \mathrm{kV}$. The nebulizer gas and collision gas was nitrogen. The collision energy was $25 \mathrm{eV}$. Full-scan MS and target MS2 spectra were obtained by scanning $\mathrm{m} / \mathrm{z}$ from 100 to 1,000 . Instrument control, data acquisition and evaluation were done with the Qexactive Tune 2.1, Chromeleon 6.8 Chromatography Data System, and Thermo Xcalibur 2.2 software, respectively. Identification of $\beta$-carotene was performed by comparison of retention times UV-visible absorbance spectra characteristics, full scan mass spectra, and MS2 fragmentation patterns with those of the standards and the literature data (Mariutti et al., 2012).

\section{CARS Microscopy}

Inoculated brick samples, saturated with different salt solutions (samples I_1, II_1, II_3, III_1 and IV_1, respectively) were grounded and attach to Nunc ${ }^{\mathrm{TM}} \mathrm{Lab}^{-\mathrm{Tek}}{ }^{\mathrm{TM}}$ chamber slide 
(Thermo Fisher Scientific, USA). Microscopy analysis of each sample was based on the Coherent Anti-stokes Raman Scattering (CARS) technology, which involves two photon excitation to visualize the vibrational contrast of molecules in specimens. The multimodal non-linear microscope consisted of inverted microscope Leica DMi8 equipped with the Leica TCS SP8 CARS module and confocal module Leica SP8 (Leica Microsystems, Germany). The Leica TCS SP8 CARS uses a tunable pump laser with a tuning range from 780 to $940 \mathrm{~nm}$, combined with a Stokes laser at $1064 \mathrm{~nm}$, provided by Laser Pico Emerald integrated with Optical Parametric Oscillator (OPO) of $750 \mathrm{~mW}$ power. System covers all Raman shifts in the range of $1,250-3,400 \mathrm{~cm}^{-1}$ wavenumbers, divided into two filter set ranging from 1,250 to $2,000 \mathrm{~cm}^{-1}$ and $2,000-3,500 \mathrm{~cm}^{-1}$. Images were taken on a CARS filter set $2,000-3,500 \mathrm{~cm}^{-1}$ and analyzed with Leica software Leica Application Suite X (LAS X) Version 2.0. Settings were set as follows: (1) sequential scanning: scan1-bright field, scan 2-CARS; (2) objective: $63 \times$; (3) immersion: water; (4) bright field scan on confocal microscope: white light laser, Ex. $488 \mathrm{~nm}$, intensity: 15,0 / 20,0\%, TLD (transmitted light detector); (5) CARS scan: Raman shift $2850 \mathrm{~cm}^{-1}$ optimal for lipid fraction in the sample, best signal for organic material probing the $\mathrm{C}$ $\mathrm{H}$ vibration, PMT (photomultiplier tubes) detector. Zoom was adjusted individually to each sample due to different particle size.

\section{Optical Measurements}

Color parameters were checked for each inoculated sample, saturated with salt solutions (samples I_1, II_1, III_1, IV_1). Uninoculated samples immersed in corrosive salt solutions (samples I, II, III, IV) were served as controls. The measurements of color were performed with Chroma meter Minolta CR400 with Spectra Magic NX 1.3 software (Konica Minolta, Japan) under the CIEL*a* b* color space. The CIE (Commission International de l'Eclairage) color values, $\mathrm{L}^{*}$ (lightness, from 0 black to 100-white), a* (from (-50)-green to 50-red) and $b^{*}$ (from (-50)-blue to 50-yellow), were determined. The total color change $(\Delta E)$ was calculated as follows:

$$
\Delta E=\sqrt{\Delta L^{* 2}+\Delta a^{* 2}+\Delta b^{* 2}}
$$

\section{RESULTS AND DISCUSSION}

The main objective of the present study was to identify the pattern of metabolic responses by halophilic microorganisms exposed to different salts present in brick samples. For this purpose, we sought to isolate groups of metabolites potentially responsible for the degradation of building materials, as well as those that play a vital role in haloadaptation to severe saline conditions.

The metabolome was found to be largest in the sample saturated with $\mathrm{MgSO}_{4}$ (838 compounds) and smallest in the sample saturated with $\mathrm{KCl}$ solution (574 compounds). The numbers of putative identifications were noticeably different between samples (Table 2). Similarities and differences between the samples from different backgrounds separated into distinct clusters, as defined by principal component analysis (PCA) plots
TABLE 2 | Putative compounds in each sample.

\begin{tabular}{lcccc}
\hline Sample & $\begin{array}{c}\text { Total } \\
\text { metabolome }^{\mathbf{a}}\end{array}$ & $\begin{array}{c}\text { Putative } \\
\text { identifications }^{\mathbf{b}}\end{array}$ & $\begin{array}{c}\text { Discriminative } \\
\text { metabolites }^{\mathbf{c}}\end{array}$ \\
\hline $\mathrm{KCl}$ & 574 & 116 & 71 \\
$\mathrm{NaCl}$ & 1st cycle & 698 & 119 & 36 \\
& 3rd cycle & 685 & 117 & 148 \\
$\mathrm{MgSO}_{4}$ & 838 & 171 & 161 \\
$\mathrm{Mg}\left(\mathrm{NO}_{3}\right)_{2}$ & 810 & 173 & 113 \\
\hline
\end{tabular}

a The total number of compounds summed from each sample.

${ }^{b}$ In the total metabolome.

cIn the total metabolome; metabolites involved in separation of inoculated sample cluster.

(Figure 2). According to the PCA model, total variance of the data was $55.3 \%$, with $34.8 \%$ and $20.5 \%$ attributed to PC1 and PC2, respectively, and an additional $19.4 \%$ contributed by PC3 (10.3\%) and PC4 (9.1\%). PC1 and PC2 results (Figure 2A) show clear clustering of inoculated and uninoculated samples. The samples saturated with different salt solutions and inoculated with mixed cultures of halophilic microorganisms are spread across two different clusters. The first cluster (red dashed line) is dominated by the inoculated brick samples exposed to the corrosive effect of $\mathrm{KCl}, \mathrm{NaCl}$ (1st cycle), and $\mathrm{MgSO}_{4}$. The second cluster (orange dashed line) contains exclusively the inoculated samples saturated with $\mathrm{Mg}\left(\mathrm{NO}_{3}\right)_{2}$ and $\mathrm{NaCl}$ (3rd cycle). By comparison, results defined by PC3 and PC4 (Figure 2B) show structured responses to different salt types. Chloride salts (blue dashed line) and magnesium salts (navy dashed line) are clustered separately, as are samples exposed to 3 cycles of $\mathrm{NaCl}$ (purple dashed line), which also form a distinct group. Such clustering may be explained by previous findings, whereby halophiles isolated from historical artifacts showed higher tolerance to magnesium salts (Oren, 1994; Saiz-Jimenez and Laiz, 2000). This feature may play an important role in haloadaptation (De Medicis, 1986). In contrast, a minimum concentration of $\mathrm{Na}^{+}$ions is sufficient for growth, due to their impact on transport processes in the cell membrane (Ventosa et al., 1998). According to the literature, $\mathrm{Mg}^{2+}$ ions are required for activation of biosynthetic systems, whereas $\mathrm{KCl}$ and $\mathrm{NaCl}$ have a mostly inhibitory effect (Stern and Tietz, 1978; Oren, 2002). Here, PCA plots were constructed based on an unsupervised method and thus only a qualitative separation is showed. PCA allowed us to detect sample patterns and the differences between them. As the latter remained somewhat unclear, we used partial least squares discriminant analysis (PLS-DA) to achieve a better separation between samples and evaluate the causative factors for the observed clustering (Figure 2C). The PLS-DA plot based on putatively identified metabolites, revealed a clear separation between uninoculated (dark green dashed line) and inoculated samples (light green dashed line). Accordingly, the abundances (concentrations) of putative metabolites may be related to the microorganisms themselves and their ability to produce metabolites potentially associated with brick deterioration, rather than a specific type of salt. Figure 2 presents strong evidence for the existence of clear metabolic differentiation as a consequence of halophile response to a saline environment. 

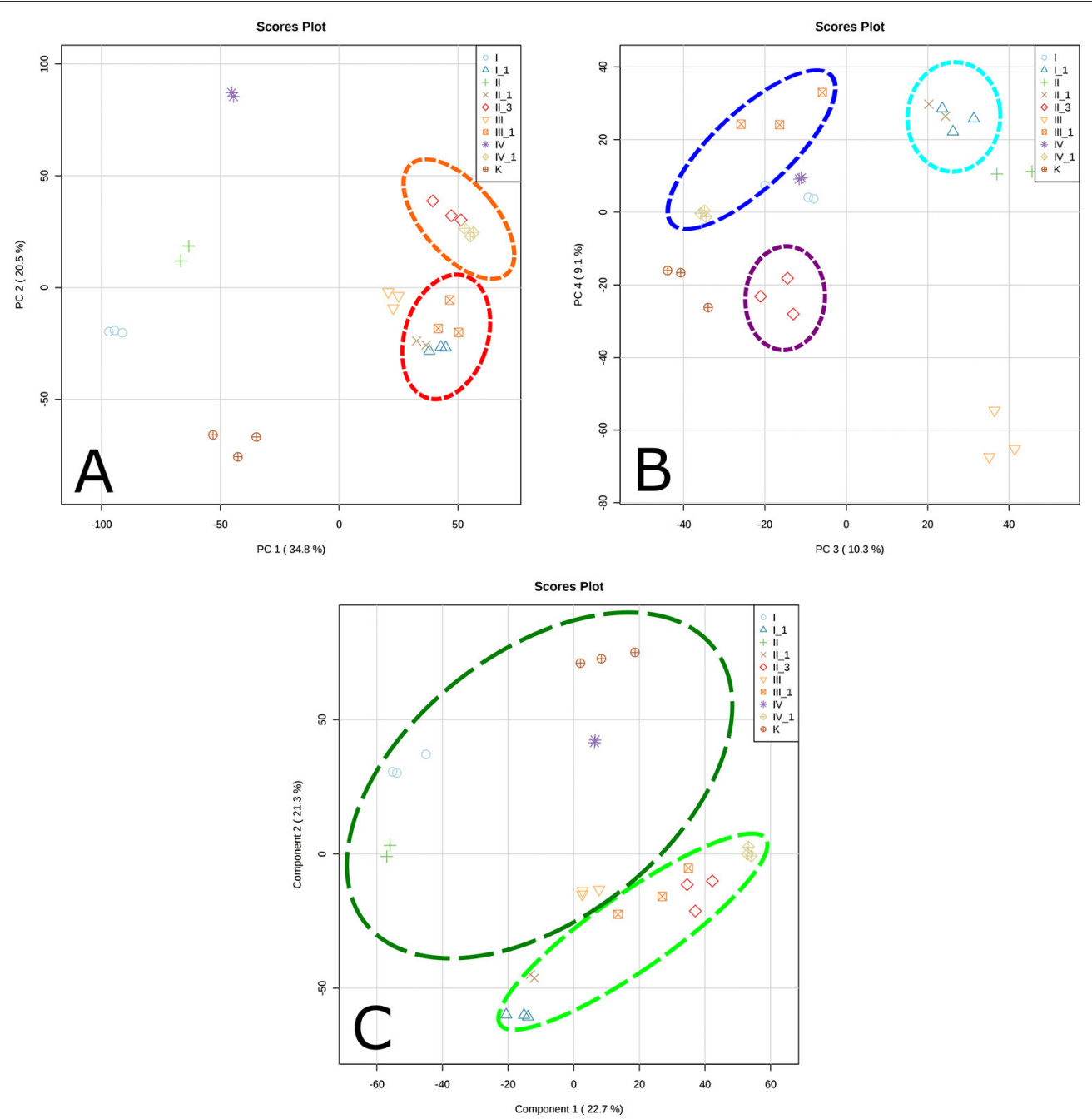

FIGURE 2 | Principal Component Analysis (PCA) plot based on putatively identified metabolites (metabolomic data from each triplicate analysis of each of the samples): (A) PC 1 and PC 2, (B) PC 3 and PC 4, (C) corresponding PLS-DA plot; - cluster dominated by the inoculated brick samples exposed to corrosive effect of $\mathrm{KCl}, \mathrm{NaCl}$ (1st cycle) and $\mathrm{MgSO}_{4}$; - cluster containing the inoculated samples saturated in $\mathrm{Mg}\left(\mathrm{NO}_{3}\right)_{2}$ and $\mathrm{NaCl}(3 \mathrm{rd}$ cycle); - cluster dominated by the inoculated $\mathrm{NaCl}$ and $\mathrm{KCl}$ samples; - cluster dominated by the inoculated $\mathrm{MgSO}_{4}$ and $\mathrm{Mg}\left(\mathrm{NO}_{3}\right)_{2}$ samples; - cluster containing the inoculated samples saturated in $\mathrm{NaCl}(3 \mathrm{rd}$ cycle); - cluster containing the inoculated samples; - cluster containing the uninoculated samples. I, KCl/uninoculated; I_1, KCl/inoculated; II, NaCl/uninoculated; II_1, $\mathrm{NaCl}$ (1 cycle of saturation)/inoculated; II_3, $\mathrm{NaCl}$ (3 cycles of saturation)/inoculated; III, MgSO $4 /$ uninoculated; III_1, MgSO 4 /inoculated; IV, $\mathrm{Mg}\left(\mathrm{NO}_{3}\right)_{2}$ /uninoculated; IV_1, $\mathrm{Mg}\left(\mathrm{NO}_{3}\right)_{2}$ /inoculated; $\mathrm{K}$, unsaturated/uninoculated.

Metabolomic data indicated the presence of intermediates presumably involved in 26 metabolic pathways related to both degradation of building materials and adaptation to severe saline environment (Table 3). The identified pathways included: biosynthesis and degradation of amino acids (e.g., valine, lysine, isoleucine), sulfur metabolism and carbohydrate digestion, carotenoid biosynthesis (salinixanthin), mineral absorption via sodium and chloride transporters, and glycerophospholipids metabolism, which plays a crucial role in the formation of biological membranes. A complete list of pathways and the detected intermediates is presented in Supplementary Materials 3.

Metabolomics studies have provided answers to numerous basic questions regarding the adaptation of halophiles to salty environments and their ability to degrade building materials. In our study, we found metabolites potentially involved as intermediates in metabolic pathways such as synthesis of compatible solutes (betaine). This finding supports the mechanism allowing for osmoadaptation of halophilic microorganisms found in building materials. According to the "salt-in-cytoplasm" strategy, microorganisms adapt the protein machinery of the cell to augment the salt concentration in the cytoplasm. In contrast, identification of betaine synthesis pathways supports the action of the organic-osmolyte strategy, which is based on the uptake or synthesis of organic molecules so that their concentration within the cell is regulated according to the salt concentration outside the cell. The ability of aerobic heterotrophic Bacteria to synthesize betaine has not been proved 
TABLE 3 | The list of metabolic pathways; annotated metabolites were involved as intermediates.

\begin{tabular}{|c|c|c|c|c|}
\hline No. & Pathway ${ }^{a}$ & Metabolites involved as intermediates ${ }^{b}$ & Formula & High abundance in samples ${ }^{c}$ \\
\hline \multirow[t]{2}{*}{1} & Nicotinate and nicotinamide metabolism & & $\mathrm{C}_{21} \mathrm{H}_{28} \mathrm{~N}_{7} \mathrm{O}_{14} \mathrm{P}_{2}$ & All \\
\hline & & Nicotinurate & $\mathrm{C}_{8} \mathrm{H}_{8} \mathrm{~N}_{2} \mathrm{O}_{3}$ & \\
\hline \multirow[t]{2}{*}{2} & Pantothenate and CoA biosynthesis & (R)-4'-Phosphopantothenoyl-L-cysteine & $\mathrm{C}_{12} \mathrm{H}_{23} \mathrm{~N}_{2} \mathrm{O}_{9} \mathrm{PS}$ & $\mathrm{KCl}, \mathrm{NaCl}, \mathrm{Mg}\left(\mathrm{NO}_{3}\right)_{2}$ \\
\hline & & L-Valine & $\mathrm{C}_{5} \mathrm{H}_{11} \mathrm{NO}_{2}$ & \\
\hline 3 & Aminoacyl-tRNA biosynthesis & L-Valine & $\mathrm{C}_{5} \mathrm{H}_{11} \mathrm{NO}_{2}$ & $\mathrm{KCl}, \mathrm{NaCl}, \mathrm{Mg}\left(\mathrm{NO}_{3}\right)_{2}$ \\
\hline 4 & Carotenoid biosynthesis & Salinixanthin & $\mathrm{C}_{51} \mathrm{H}_{78} \mathrm{O}_{8}$ & All \\
\hline 5 & $\begin{array}{l}\text { Mineral absorption via sodium- and } \\
\text { chloride-dependent transporter }\end{array}$ & L-Valine & $\mathrm{C}_{5} \mathrm{H}_{11} \mathrm{NO}_{2}$ & All \\
\hline 6 & Cysteine and methionine metabolism & 3-(Methylthio)propionic acid & $\mathrm{C}_{4} \mathrm{H}_{8} \mathrm{O}_{2} \mathrm{~S}$ & $\mathrm{Mg}\left(\mathrm{NO}_{3}\right)_{2}$ \\
\hline 7 & Lysine biosynthesis & N-Succinyl-LL-2,6-diaminoheptanedioate & $\mathrm{C}_{11} \mathrm{H}_{18} \mathrm{~N}_{2} \mathrm{O}_{7}$ & $\mathrm{NaCl}, \mathrm{Mg}\left(\mathrm{NO}_{3}\right)_{2}$ \\
\hline 8 & Lysine degradation & 5-Aminopentanoate & $\mathrm{C}_{5} \mathrm{H}_{11} \mathrm{NO}_{2}$ & $\mathrm{KCl}, \mathrm{NaCl}, \mathrm{Mg}\left(\mathrm{NO}_{3}\right)_{2}$ \\
\hline 9 & Oxidative phosphorylation & $\mathrm{NAD}+$ & $\mathrm{C}_{21} \mathrm{H}_{28} \mathrm{~N}_{7} \mathrm{O}_{14} \mathrm{P}_{2}$ & All \\
\hline 10 & Photosynthesis & Plastoquinol-1 & $\mathrm{C}_{13} \mathrm{H}_{18} \mathrm{O}_{2}$ & $\mathrm{NaCl}$ \\
\hline 11 & Sulfur metabolism & 3-(Methylthio)propionic acid & $\mathrm{C}_{4} \mathrm{H}_{8} \mathrm{O}_{2} \mathrm{~S}$ & $\mathrm{Mg}\left(\mathrm{NO}_{3}\right)_{2}$ \\
\hline 12 & Arginine and proline metabolism & 5-Aminopentanoate & $\mathrm{C}_{5} \mathrm{H}_{11} \mathrm{NO}_{2}$ & $\mathrm{KCl}, \mathrm{NaCl}, \mathrm{Mg}\left(\mathrm{NO}_{3}\right)_{2}$ \\
\hline 13 & Phenylalanine metabolism & Phenethylamine & $\mathrm{C}_{8} \mathrm{H}_{11} \mathrm{~N}$ & $\mathrm{KCl}, \mathrm{NaCl}, \mathrm{Mg}\left(\mathrm{NO}_{3}\right)_{2}$ \\
\hline 14 & Thiamine metabolism & NAD+ & $\mathrm{C}_{21} \mathrm{H}_{28} \mathrm{~N}_{7} \mathrm{O}_{14} \mathrm{P}_{2}$ & All \\
\hline 15 & Valine, leucine and isoleucine biosynthesis & L-Valine & $\mathrm{C}_{5} \mathrm{H}_{11} \mathrm{NO}_{2}$ & $\mathrm{KCl}, \mathrm{NaCl}, \mathrm{Mg}\left(\mathrm{NO}_{3}\right)_{2}$ \\
\hline 16 & Valine, leucine and isoleucine degradation & L-Valine & $\mathrm{C}_{5} \mathrm{H}_{11} \mathrm{NO}_{2}$ & $\mathrm{KCl}, \mathrm{NaCl}, \mathrm{Mg}\left(\mathrm{NO}_{3}\right)_{2}$ \\
\hline 17 & Glycine, serine and threonine metabolism & Betaine & $\mathrm{C}_{5} \mathrm{H}_{11} \mathrm{NO}_{2}$ & $\mathrm{KCl}, \mathrm{NaCl}, \mathrm{MgSO}_{4}$ \\
\hline 18 & Histidine metabolism & Ergothioneine & $\mathrm{C}_{9} \mathrm{H}_{16} \mathrm{~N}_{3} \mathrm{O}_{2} \mathrm{~S}$ & All \\
\hline 19 & Glucosinolate biosynthesis & L-Valine & $\mathrm{C}_{5} \mathrm{H}_{11} \mathrm{NO}_{2}$ & $\mathrm{KCl}, \mathrm{NaCl}, \mathrm{Mg}\left(\mathrm{NO}_{3}\right)_{2}$ \\
\hline 20 & Cyanoamino acid metabolism & L-Valine & $\mathrm{C}_{5} \mathrm{H}_{11} \mathrm{NO}_{2}$ & $\mathrm{KCl}, \mathrm{NaCl}, \mathrm{Mg}\left(\mathrm{NO}_{3}\right)_{2}$ \\
\hline 21 & Butanoate metabolism & Butanoic acid & $\mathrm{C}_{4} \mathrm{H}_{8} \mathrm{O}_{2}$ & $\mathrm{KCl}, \mathrm{NaCl}, \mathrm{MgSO}_{4}, \mathrm{Mg}\left(\mathrm{NO}_{3}\right)_{2}$ \\
\hline 22 & Methane metabolism & Methanofuran & $\mathrm{C}_{34} \mathrm{H}_{44} \mathrm{~N}_{4} \mathrm{O}_{15}$ & $\mathrm{MgSO}_{4}$ \\
\hline \multirow[t]{2}{*}{23} & Sphingolipid metabolism & 3-Dehydrosphinganine & $\mathrm{C}_{18} \mathrm{H}_{37} \mathrm{NO}_{2}$ & $\mathrm{KCl}, \mathrm{MgSO}_{4}$ \\
\hline & & Phytosphingosine & $\mathrm{C}_{18} \mathrm{H}_{39} \mathrm{NO}_{3}$ & \\
\hline \multirow[t]{2}{*}{24} & Glycerophospholipid metabolism & Phosphatidylcholine & $\mathrm{C}_{10} \mathrm{H}_{18} \mathrm{NO}_{8} \mathrm{PR}_{2}$ & All \\
\hline & & Phosphatidylethanolamine & $\mathrm{C}_{7} \mathrm{H}_{12} \mathrm{NO}_{8} \mathrm{PR}_{2}$ & \\
\hline \multirow[t]{2}{*}{25} & Primary bile acid biosynthesis & 7alpha-Hydroxycholest-4-en-3-one & $\mathrm{C}_{27} \mathrm{H}_{44} \mathrm{O}_{2}$ & All \\
\hline & & Chenodeoxycholate & $\mathrm{C}_{24} \mathrm{H}_{40} \mathrm{O}_{4}$ & \\
\hline 26 & Secondary bile acid biosynthesis & Chenodeoxycholate & $\mathrm{C}_{24} \mathrm{H}_{40} \mathrm{O}_{4}$ & All \\
\hline
\end{tabular}

a Metabolic pathways related to both degradation of building materials and adaptation to severe saline environment.

${ }^{b}$ Putatively annotated compounds, Level 2 (Sumner et al., 2007).

cInoculated brick samples saturated in the following corrosive salt solution.

yet; however, betaine synthesis was reported in phototrophic Bacteria and Archaea via the serine pathway with choline as an intermediate (Kunte et al., 2002). Besides playing a crucial role in haloadaptation, compatible solutes can stabilize proteins or even whole cells, protecting them against heat, desiccation, freezing and thawing, and denaturants such as urea (Lippert and Galinski, 1992; Kunte et al., 2002). Interestingly, it was found that members of the genus Halobacillus, which are mainly chloride-dependent bacteria, were able to switch their osmolyte strategy as a consequence of changing salinity (Ma et al., 2010). Moreover, our results showed also the biosynthesis of a ketocarotenoid similar to salinixanthin. One of the possible ways for its formation is synthesis from $\beta$-carotene. The formation of ketolated carotenoids from $\beta$-carotene is rather rare and was observed for the first time for marine bacteria (Ralley et al., 2004). UPLC coupled to diode-array detector electrospray ionization mass spectrometry (UHPLC-DAD-ESI-MS) of inoculated brick samples confirmed, however, the presence of $\beta$-carotene (Supplementary Materials 4), thus supporting the above-mentioned theory. $\beta$-carotene was present in every inoculated brick sample, but was most abundant in the sample saturated with $\mathrm{KCl}$ solution. This finding emphasizes the destructive potential of halophilic microorganisms, in particular their ability to cause aesthetic changes on the surface of buildings. The changes in color of inoculated brick samples immersed in corrosive salt solutions, were corroborated by spectrophotometric measurements using the CIEL*a*b* system (Table 4). Thus, inoculation with halophilic microorganisms and yearlong incubation at $28^{\circ} \mathrm{C}$ and $80 \%$ relative humidity resulted in a statistically significant increase in brightness $\left(\mathrm{L}^{*}\right)$, a decrease in redness $\left(\mathrm{a}^{*}\right)$ and yellowness $\left(\mathrm{b}^{*}\right)$, as well as a total color change exceeding a value of 5 on the surface of samples. Generally speaking, salty deposits mimic extreme saline habitats, hostile to halophilic microorganisms and contribute to further contamination of building materials, which may be observed as yellowish to reddish discolorations caused by production of carotenoids. Primarily, pigment formation is associated with a response against photooxidative damage, chemical, and/or salt stress. On salt-attacked objects, biogenic pigments are usually very resistant, even after the microorganisms' death (Piñar et al., 
TABLE 4 | Color parameters of brick samples.

\begin{tabular}{|c|c|c|c|c|c|c|c|}
\hline \multirow{2}{*}{$\begin{array}{l}\text { Corrosive salt } \\
\text { solution }\end{array}$} & & \multicolumn{3}{|c|}{ Uninoculated sample } & \multicolumn{3}{|c|}{ Inoculated sample } \\
\hline & & $\mathbf{L}^{*}$ & $a^{*}$ & $\mathbf{b}^{*}$ & $\mathbf{L}^{*}$ & $a^{*}$ & $\mathbf{b}^{*}$ \\
\hline \multirow[t]{3}{*}{$\mathrm{KCl}$} & & M: 43.35 & $M: 24.11$ & $M: 25.51$ & $M^{a}: 44.64$ & $M^{a}: 19.38$ & $M^{a}: 19.94$ \\
\hline & & SD: 0.89 & SD: 0.64 & $S D: 0.65$ & $S D: 1.04$ & SD: 0.92 & $S D: 0.74$ \\
\hline & & & & & & $\Delta \mathrm{E}: 7.43$ & \\
\hline \multirow[t]{6}{*}{$\mathrm{NaCl}$} & 1st cycle & & & & $M^{a}: 45.36$ & $M^{a}: 19.91$ & $M^{a}: 19.81$ \\
\hline & & & & & $S D: 0.80$ & $S D: 1.29$ & $S D: 1.07$ \\
\hline & & M: 43.35 & $M: 24.11$ & $M: 25.51$ & & $\Delta \mathrm{E}: 7.36$ & \\
\hline & 3rd cycle & $S D: 0.89$ & $S D: 0.64$ & $S D: 0.65$ & $M^{a}: 36.75$ & $M^{a}: 19.96$ & $M^{a}: 20.97$ \\
\hline & & & & & $S D: 1.65$ & $S D: 1.11$ & $S D: 1.26$ \\
\hline & & & & & & $\Delta \mathrm{E}: 9.02$ & \\
\hline \multirow[t]{3}{*}{$\mathrm{MgSO}_{4}$} & & M: 43.29 & M: 23.16 & M: 23.64 & $M^{a}: 48.59$ & $M^{a}: 17.67$ & $M^{a}: 18.50$ \\
\hline & & $S D: 1.63$ & $S D: 0.74$ & $S D: 0.98$ & $S D: 0.79$ & $S D: 0.97$ & $S D: 0.31$ \\
\hline & & & & & & $\Delta \mathrm{E}: 9.20$ & \\
\hline \multirow[t]{3}{*}{$\mathrm{Mg}\left(\mathrm{NO}_{3}\right)_{2}$} & & M: 41.85 & M: 20.73 & M: 21.98 & $M^{a}: 45.38$ & $M^{a}: 15.24$ & $M^{a}: 18.52$ \\
\hline & & $S D: 0.64$ & $S D: 1.36$ & $S D: 0.75$ & $S D: 1.49$ & $S D: 1.14$ & $S D: 1.30$ \\
\hline & & & & & & $\Delta \mathrm{E}: 7.39$ & \\
\hline
\end{tabular}

$M$, arithmetic mean; $S D$, standard deviation; $L^{*}$, lightness; $a^{*}$, red-green axis; $b^{*}$, yellow-blue axis; $\Delta E$, total color change.

a Statistically significant differences between inoculated samples saturated in corrosive salt solutions and uninoculated samples saturated in corrosive salt solutions (analysis of variance, ANOVA, $p<0.05)$.

2014). Previous studies held by Ettenauer et al. (2014) and Piñar et al. (2014) on objects of art, revealed that microbial metabolites, especially pigments, altered building elements, and were thus major contributors to biodeterioration. Here, the biocorrosive potential of halophilic microorganisms was also proved by the formation of trace amounts of acids, in particular acetic acid (Supplementary Materials 5). Organic acids are known to be major causes of biodeterioration of building materials (Gutarowska and Czyzowska, 2009).

Among putative metabolites, lipids were one of the dominant compound groups. They provide information pertaining to an organism's actual phenotype, variety of structural and functional properties, cellular architecture, and function (Harkewicz and Dennis, 2011). Among lipids, phospholipids (PLs) were the most abundant category, particularly neutrally charged phosphatidylethanolamine (PE) and phosphatidylcholine (PC), and negatively charged phosphatidylserine (PS), phosphatidylinositol (PI), and phosphatidylglycerol (PG). As expected, hierarchical clustering (Figure 3) showed a different lipid pattern in the sample exposed to higher salinity (sample II_3). Exposure to 3 cycles of a $\mathrm{NaCl}$ corrosive environment induced a decrease in the concentration of PS, while only slightly reducing the concentration of PE. A specific PL composition may be essential for haloadaptation (Oren, 2002). Any change in lipid composition resulting from exposure to a saline environment is due to preservation of the membrane's bilayer structure. To preserve its integrity, a correct proportion of bilayer-forming and non-bilayer-forming PLs is required. Generally, PE tends to form non-bilayer phases, whereas PG forms a stable bilayer. In this respect, increasing salinity results in an increase of negatively charged PLs at the expense of PE. Accordingly, the slightly lower PE concentration observed in our study when salinity was augmented, fits in part with this pattern, but does not allow us to draw any general conclusions. Interestingly enough, we noted a remarkable change in membrane composition due to a decrease in PS levels. This shift may be explained by immediate conversion to PE, of which PS is a precursor (Vance and Steenbergen, 2005). Furthermore, an increase in medium salinity induced an increase in the concentration of unsaturated fatty acids in the membrane. The major fatty acids detected in the sample with higher $\mathrm{NaCl}$ concentration (II_3) were C24:2 $2^{\Delta 5,13}$ and $\mathrm{C} 20: 1^{\Delta 13}$. Changes in fatty acid composition represent an important factor in the maintenance of membrane fluidity (Turk et al., 2004). Unsaturated fatty acids generally increase membrane fluidity (Oren, 2002).

Finally, we applied CARS microscopy to elucidate biodeterioration and detect single halophilic microorganisms involved in this process in situ. Figures $4 A-E$ shows a $2,850 \mathrm{~cm}^{-1}$ CARS image of the mixture of halophilic microorganisms in building material (red points in the picture). The corresponding 3D image (Figure 4F) provides a full picture of halophiles' distribution across the sample. Specifically, we examined the influence of environmental conditions (saturation in different salt solutions) on the abundance of halophilic microorganisms in building material. It is noteworthy, that in samples saturated with magnesium salts (Figures 4A,B) halophilic microorganisms are more abundant than in samples saturated with chloride salts (Figures 4C-E), which may be due to the aforementioned inhibitory effect of $\mathrm{KCl}$ and $\mathrm{NaCl}$. The average diameter of the cell was $0.80 \pm 0.08 \mu \mathrm{m}$. According to the 3D image (Figure 4F), halophiles were present across the entire sample (up to $25 \mu \mathrm{m}$ ). Although, the present study focused on halophiles detection, 


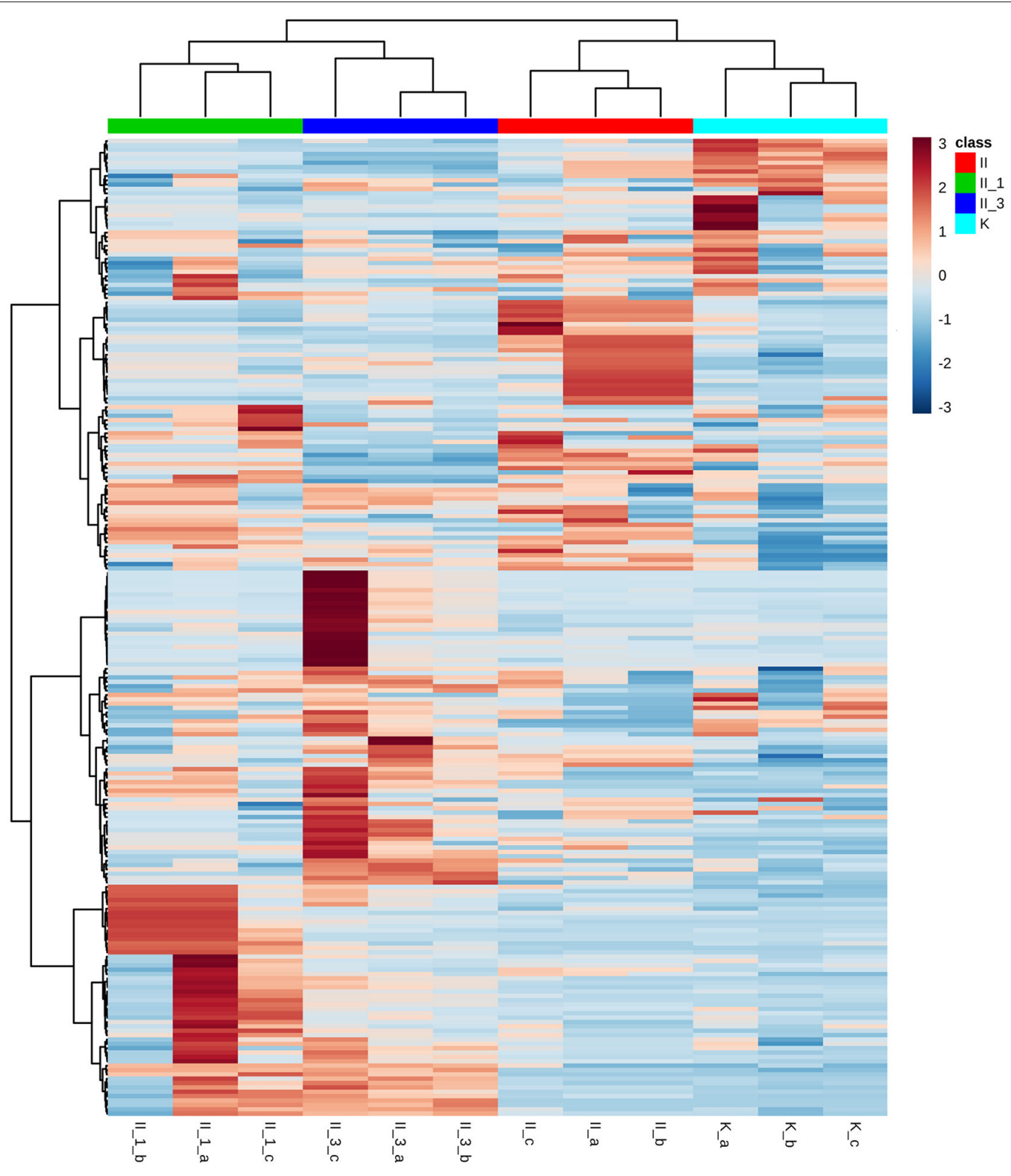

FIGURE 3 | Hierarchical clustering with lipid structure visualization; distance measure: Euclidean; clustering algorithm: Ward. Each row represents a feature, while each column represents a sample. The blue color of the tile indicates low abundance and red indicates high abundance. II, NaCl/uninoculated; II_1, NaCl (1 cycle of saturation)/inoculated; II_3, $\mathrm{NaCl}$ (3 cycles of saturation)/inoculated; K, unsaturated/uninoculated; letters a,b,c refer to the following biological replicates.

their metabolic activity may be studied by monitoring spectral changes (Hellerer et al., 2007) and thus provide clues of how haloadaptation occurs. In particular, viability of halophiles entrapped in small inclusions, following drying and the formation of crystals on the surface of building material, is a key topic in haloadaptation (Ma et al., 2010).

\section{CONCLUSIONS AND FUTURE CHALLENGES}

The main focus of the present study was to find a relationship between metabolomic data and activity of halophilic microorganisms in an attempt to better understand how they contribute to biodeterioration of building materials or cope with osmotic stress. Our results clearly demonstrate the usefulness of halophilic community metabolomics. The information produced by metabolomics and its very close link to the phenotype of microorganisms makes it possible to successfully find biomarkers, which could be used for early detection of biodeterioration. In the case of halophiles, carotenoids represent possible candidates. Although we found several metabolites, many of them remained unidentified. Therefore, a reliable evaluation of biodeterioration caused by halophilic microorganisms will necessarily have to 

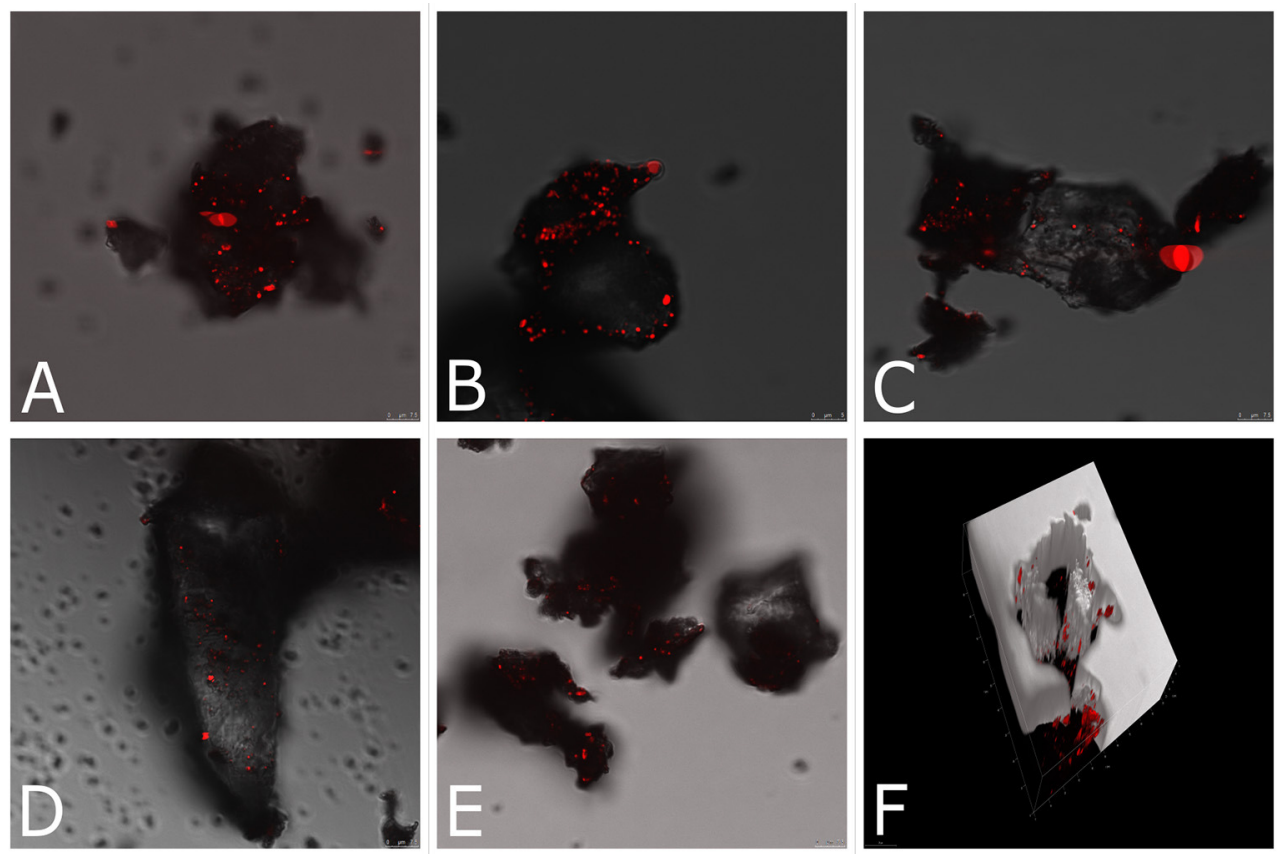

FIGURE 4 | Lipid-based CARS imaging of inoculated brick samples saturated in the following corrosive salt solutions: (A) $\mathrm{Mg}\left(\mathrm{NO}_{3}\right)_{2}$, (B) $\mathrm{MgSO}_{4}$, (C) $\mathrm{KCl}$ (D) $\mathrm{NaCl}$ 1st cycle of saturation, (E) NaCl 3rd cycle of saturation; the bright signals result from the $\mathrm{CH}_{2}$ symmetric stretch vibration of aliphatic lipid of the cells; (F) 3D distribution of halophiles across the $\mathrm{KCl}$ sample, dark interior depicts analyzed sample.

extend beyond already identified metabolites. Of particular relevance for biodeterioration studies is to combine various metabolomics methods, separation modes, and platforms to significantly improve data integration on the role played by halophilic microorganisms. This may also reveal other mechanisms of action and complex interactions in a salty environment, as the one encountered in building materials. Until now, it was challenging to rapidly detect microbes in their natural environment; however, CARS microscopy offers unique advantages in this sense. Indeed, CARS may soon become an indispensable tool for lipid-related in situ detection of a single living cell with high sensitivity and selectivity, without alterations to the sample. In the future, it may become a crucial instrument for assessing biodeterioration of cultural property caused by halophilic microorganisms, where the amount of a sample is significantly limited.

\section{AUTHOR CONTRIBUTIONS}

JA was responsible for MS analyses, data analysis, CARS microscopy analysis and took the lead in writing the manuscript. VB conducted MS analyses and assisted with data analysis and writing. AO took part in sample preparation, in particular preselection of strains and inoculation, assisted with CARS microscopy and manuscript proofreading. JS guided the MS analyses and contributed to the results proofreading. IB contributed to the MS analysis and results proofreading.
TS was responsible for the brick sample preparation, especially saturation with salty corrosive solutions. SK was involved in collecting the brick samples and their further preparation. JO was involved in $\beta$-carotene identification, optical measurements and manuscript proofreading. DZ contributed to the determination of color parameters and manuscript proofreading. BG contributed to the ideas, writing and editing the manuscript.

\section{FUNDING}

The authors have received funding from the Polish National Science Centre (ETIUDA 4; grant number UMO-2016/20/T/NZ9/00569) for supporting PhD students.

\section{ACKNOWLEDGMENTS}

We would like to acknowledge S. Foster, PhD (The University of Oklahoma, USA) for support in mass spectrometry analysis, K. Kubiak, PhD and J. Jaros, MSc (BioNanoPark, Lodz, Poland) for CARS microscopy measurements and suggestions related to the analysis.

\section{SUPPLEMENTARY MATERIAL}

The Supplementary Material for this article can be found online at: https://www.frontiersin.org/articles/10.3389/fmicb. 2017.02448/full\#supplementary-material 


\section{REFERENCES}

Adamiak, J., Otlewska, A., and Gutarowska, B. (2015). Halophilic microbial communities in deteriorated buildings. World J. Microbiol. Biotechnol. 31, 1489-1499. doi: 10.1007/s11274-015-1913-3

Adamiak, J., Otlewska, A., Gutarowska, B., and Pietrzak, A. (2016). Halophilic microorganisms in deteriorated historic buildings: insights into their characteristics. Acta Biochim. Pol. 63, 335-334. doi: 10.18388/abp.2015_1171

Averhoff, B., and Müller, V. (2010). Exploring research frontiers in microbiology: recent advances in halophilic and thermophilic extremophiles. Res. Microbiol. 161, 506-514. doi: 10.1016/j.resmic.2010.05.006

Baidoo, E. E., Benke, P. I., and Keasling, J. D. (2012). Mass spectrometrybased microbial metabolomics. Methods Mol. Biol. 881, 215-278. doi: 10.1007/s00216-014-8127-7.

Barkal, L. J., Theberge, A. B., Guo, C. J., Spraker, J., Rappert, L., Berthier, J., et al. (2015). Microbial metabolomics in open microscale platforms. Nature 7:10610. doi: 10.1038/ncomms10610

Bonifay, V., Wawrik, B., Sunner, J., Snodgrass, E. C., Aydin, E., and Duncan, K. E., et. al. (2017). Metabolomic and metagenomic analysis of two crude oil production pipelines experiencing differential rates of corrosion. Front. Microbiol. 8:99. doi: 10.3389/fmicb.2017.00099

Brauer, J. I., Makama, Z., Bonifay, V., Aydin, E., Kaufman, E. D., Beech, I. B., et al. (2015). Mass spectrometric metabolomic imaging of biofilms on corroding steel surfaces using laser ablation and solvent capture by aspiration. Biointerphases 10:019003. doi: 10.1116/1.4906744

Caspi, R., Altman, T., Billington, R., Dreher, K., Foerster, H., Fulcher, C. A., et al. (2014). The MetaCyc database of metabolic pathways and enzymes and the BioCyc collection of pathway/genome databases. Nucleic Acids Res. 42, D459-D471. doi: 10.1093/nar/gkt1103

Cheng, J. X., and Xie, X. S. (2004). Coherent anti-stokes Raman scattering microscopy: instrumentation, theory, and applications. J. Phys. Chem. B. 108, 827-840. doi: 10.1021/jp035693v

Cheng, J. X., Volkmer, A., and Xie, X. S. (2002). Theoretical and experimental character-ization of coherent anti-Stokes Raman scattering microscopy. J. Opt. Soc. Am. B. 19, 1363-1375. doi: 10.1364/JOSAB.19.001363

Creek, D. J., Jankevics, A., Breitling, R., Watson, D. G., Barrett, M. P., and Burges, K. E. (2011). Toward global metabolomics analysis with hydrophilic interaction liquid chromatography mass spectrometry: improved metabolite identification by retention time prediction. Anal. Chem. 83, 8703-8710. doi: $10.1021 /$ ac2021823

Creek, D. J., Jankevics, A., Burgess, K. E., Breitling, R., and Barrett, M. P. (2012). IDEOM: an Excel interface for analysis of LC-MS-based metabolomics data. Bioinformatics 28, 1048-1049. doi: 10.1093/bioinformatics/bts069

De Medicis, E. (1986). Magnesium, manganese and mutual depletion systems in halophilic bacteria. FEMS Microbiol. Rev. 37, 137-143. doi: 10.1111/j.1574-6968.1986.tb01854.x

Ettenauer, J. D., Jurado, V., Piñar, G., Miller, A. Z., Santner, M., Saiz-Jimenez, C., et al. (2014). Halophilic microorganisms are responsible for the rosy discolouration of saline environments in three historical buildings with mural paintings. PLoS ONE 9:103844. doi: 10.1371/journal.pone.0103844

Fahy, E., Subramaniam, S., Murphy, R. C., Nishijima, M., Raetz, C. R., Shimizu, T., et al. (2009). Update of the LIPID MAPS comprehensive classification system for lipids. J. Lipid Res. 50, S9-S14. doi: 10.1194/jlr.R800095-JLR200

Folick, A., Min, W., and Wang, M. C. (2011). Label-free imaging of lipid dynamics using Coherent Anti-stokes Raman Scattering (CARS) and Stimulated Raman Scattering (SRS) microscopy. Curr. Opin. Genet. Dev. 21, 585-590. doi: 10.1016/j.gde.2011.09.003

Gutarowska, B., and Czyzowska, A. (2009). The ability of filamentous fungi to produce to produce acids on indoor building materials. Ann. Microbiol. 59, 807-813. doi: 10.1007/BF03179227

Gutarowska, B., Celikkol-Aydin, S., Bonifay, V., Otlewska, A., Aydin, E., Oldham, A. L., et al. (2015). Metabolomic and high-throughput sequencing analysis - modern approach for the assessment of biodeterioration of materials from historic buildings. Front. Microbiol. 6:979. doi: 10.3389/fmicb.2015.00979

Harkewicz, R., and Dennis, E. A. (2011). Applications of mass spectrometry to lipids and membranes. Annu. Rev. Biochem. 80, 301-325. doi: 10.1146/annurev-biochem-060409-092612
Hellerer, T., Axäng, C., Brackmann, C., Hillertz, P., Pilon, M., and Enejder, A. (2007). Monitoring of lipid storage in Caenorhabditis elegans using coherent anti-Stokes Raman scattering (CARS) microscopy. PNAS 104, 14658-14663. doi: 10.1073/pnas.0703594104

Heyrman, J., Mergaert, J., Denys, R., and Swings, J. (1999). The use of fatty acid methyl ester analysis (FAME) for the identification of heterotrophic bacteria present on three mural paintings showing severe damage by microorganisms. FEMS Microbiol. Lett. 181, 55-62. doi: 10.1111/j.1574-6968.1999.tb08826.x

Hong, W., Liao, C.-S., Zhao, H., Younis, W., Zhang, Y., Seleem, M. N., et al. (2016). In situ detection of a single bacterium in complex environment by hyperspectral CARS Imaging. ChemistrySelect. 3, 513-517. doi: 10.1002/slct.201600166

Kanehisa, M., Goto, S., Sato, Y., Kawashima, M., Furumichi, M., and Tanabe, M. (2014). Data, information, knowledge and principle: back to metabolism in KEGG. Nucleic Acids Res. 42, D199-D205. doi: 10.1093/nar/gkt1076

Kunte, H. J., Trüper, H. G., and Stan-Lotter, H. (2002). "Halophilic microorganisms," in Astrobiology, eds G. Horneck and C. Baumstark-Khan (Berlin: Springer), 185-200.

Laiz, L., Miller, A. Z., Jurado, V., Akatova, E., Sanchez-Moral, S., Gonzalez, J. M., et al. (2009). Isolation of five Rubrobacter strains from biodeteriorated monuments. Naturwissenschaften 96, 71-79. doi: 10.1007/s00114-008-0452-2

Laiz, L., Recio, D., Hermosin, B., and Saiz-Jimenez, C. (2000). "Microbial communities in salt efflorescences," in Of Microbes and Art, eds O. Cifferi, P. Tiano, and G. Mastromei (New York, NY: Springer), 77-88.

Lenhart, T. R., Duncan, K. E., Beech, I. B., Sunner, J. A., Smith, W., Bonifay, V., et al. (2014). Identification and characterization of microbial biofilm communities associated with corroded oil pipeline surfaces. Biofouling 30, 823-835. doi: 10.1080/08927014.2014.931379

Lippert, K., and Galinski, E. A. (1992). Enzyme stabilization by ectoine-type compatible solutes: protection against heating, freezing and drying. Appl. Microbiol. Biotechnol. 37, 61-65. doi: 10.1007/BF00174204

Ma, Y., Galinski, E. A., Grant, W. D., Oren, A., and Ventosa, A. (2010). Halophiles 2010: life in saline environments. Appl. Environ. Microbiol. 76, 6971-6981. doi: 10.1128/AEM.01868-10

Madigan, M. T., and Oren, A. (1999). Thermophilic and halophilic extremophiles. Curr. Opin. Microbiol. 2, 265-269. doi: 10.1016/S1369-5274(99)80046-0

Mariutti, L. R., Pereira, D. M., Mercadante, A. Z., Valentão, P., Teixeira, N., and Andrade, P. B. (2012). Further insights on the carotenoid profile of the echinoderm Marthasterias glacialis L. Mar. Drugs 10, 1498-1510. doi: $10.3390 / \mathrm{md} 10071498$

Mashego, M. R., Rumbold, K., De Mey, E., Vandamme, E., Soetaert, W., and Heijnen, J. J. (2007). Microbial metabolomics: past, present and future methodologies. Biotechnol. Lett. 29, 1-16. doi: 10.1007/s10529-006-9218-0

Oren, A. (1994). The ecology of the extremely halophilic archaea. FEMS Microbiol. Rev. 13, 415-440. doi: 10.1111/j.1574-6976.1994.tb00060.x

Oren, A. (2002). Halophilic Microorganisms and their Environments. New York, NY: Kluwer Academic Publishers.

Otlewska, A., Adamiak, J., Stryszewska, T., Kanka, S., and Gutarowska, B. (2017). Factors determining biodiversity of halophilic microorganisms on historic masonry buildings. Microbes Environ. 32, 164-173. doi: $10.1264 /$ jsme2.ME16159

Piñar, G., Ettenauer, J., and Sterflinger, K. (2014). "La vie en rose: A review of the rosy discoloration of subsurface monuments," in The Conservation of Subterranean Cultural Heritage, ed C. Saiz-Jimenez (Leiden: CRC Press/Balkema), 113-124.

Piñar, G., Ramos, C., Rölleke, S., Schabereiter-Gurtner, C., Vybiral, D., Lubitz, W., et al. (2001). Detection of indigenous Halobacillus population in damaged ancient wall paintings and building materials: molecular monitoring and cultivation. Appl. Environ. Microbiol. 67, 4891-4895. doi: 10.1128/AEM.67.10.4891-4895.2001

Piñar, G., Ripka, K., Weber, J., and Sterflinger, K. (2009). The micro-biota of a sub-surface monument the medival chapel of St. Virgil (Vienna, Austria). Int. Biodeterior. Biodegradation 63, 851-859. doi: 10.1016/j.ibiod.2009.02.004

Ralley, L., Enfissi, E. M., Misawa, N., Schuch, W., Bramley, P. M., and Fraser, P. D. (2004). Metabolic engineering of ketocarotenoid formation in higher plants. Plant, J. 39, 477-486. doi: 10.1111/j.1365-313X.2004.02151.x

Ripka, K., Denner, E. B. M., Michaelsen, A., Lubitz, W., and Pi-ar, G. (2006). Molecular characterization of Halobacillus strain isolated from different 
medieval wall paintings and buildings material in Austria. Int. Biodeterior. Biodegradation 58, 124-132. doi: 10.1016/j.ibiod.2006.05.004

Rölleke, S., Witte, A., Wanner, G., and Lubitz, W. (1998). Medieval wall painting - a habitat for archaea: identification of archaea by denaturing gradient gel electrophoresis (DGGE) of PCR-amplified gene fragments coding for 16S rRNA in a medieval wall painting. Int. Biodeterior. Biodegradation 41, 85-92. doi: 10.1016/S0964-8305(98)80011-5

Rochfort, S. (2005). Metabolomics reviewed: a new omics platform technology for systems biology and implications for natural products research. J. Nat. Prod. 68, 1813-1820. doi: 10.1021/np050255w

Rodriguez, L. G., Lockett, S. J., and Holtom, G. R. (2006). Coherent anti-stokes Raman scattering microscopy: a biological review. Cytometry A 69A, 779-791. doi: 10.1002/cyto.a.20299

Saiz-Jimenez, C., and Laiz, L. (2000). Occurrence of halotolerant/halophilic bacterial communities in deteriorated monuments. Int. Biodeterior. Biodegradation 46, 319-326. doi: 10.1016/S0964-8305(00)00104-9

Scheltema, R. A., Jankevics, A., Jansen, R. C., Swertz, M. A., and Breitling, R. (2011). PeakML/mzMatch: a file format, java library, $r$ library, and tool-chain for mass spectrometry data analysis. Anal. Chem. 83, 2786-2793. doi: 10.1021/ac 2000994

Smith, C. A., Want, E. J., O'Maille, G., Abagyan, R., and Siuzdak, G. (2006). XCMS: processing mass spectrometry data for metabolite profiling using nonlinear peak alignment, matching, and identification. Anal. Chem. 78, 779-787. doi: 10.1021/ac051437y

Sterflinger, K., and Piñar, G. (2013). Microbial deterioration of cultural heritage and works of art-tilting at windmills? Appl. Microbiol. Biotechnol. 97, 9637-9646. doi: 10.1007/s00253-013-5283-1

Stern, N., and Tietz, A. (1978). Glycolipids of a halotolerant, moderately halophilic bacterium. Biosynthesis of glucosylphosphatidylglycerol by cell-free particles. Biochim. Biophys. Acta 530, 357-366. doi: 10.1016/0005-2760(78)90155-8

Stryszewska, T. (2014). The change in selected properties of ceramic materials obtained from ceramic brick treated by the sulphate and chloride ions. Construct. Building Mater. 66, 268-274. doi: 10.1016/j.conbuildmat.2014. 05.066

Sumner, L. W., Amberg, A., Barrett, D., Beale, M. H., Beger, R., Daykin, C. A., et al. (2007). Proposed minimum reporting standards for chemical analysis. Metabolomics 3, 211-221. doi: 10.1007/s11306-007-0082-2

Szulc, J., Ruman, T., and Gutarowska, B. (2017). Metabolome profiles of moulds on carton-gypsum board and malt extract agar obtained using an AuNPET SALDI-ToF-MS method. Int. Biodeterior. Biodegradation 125, 13-23. doi: 10.1016/j.ibiod.2017.08.002

Tang, J. (2011). Microbial metabolomics. Curr. Genomics 12, 391-403. doi: $10.2174 / 138920211797248619$

Tautenhahn, R., Böttcher, C., and Neumann, S. (2008). Highly sensitive feature detection for high resolution LC/MS. BMC Bioinformatics 9:504. doi: 10.1186/1471-2105-9-504

Tomlinson, G. A., and Hochstein, L. I. (1972). Studies on acid production during carbohydrate metabolism by extremely halophilic bacteria. Can. J. Microbiol. 18, 1973-1976. doi: 10.1139/m72-308
Turk, M., Méjanelle, L., Sentjurc, M., Grimalt, J. O., Gunde-Cimerman, N., and Plemenitas, A. (2004). Salt-induced changes in lipid composition and membrane fluidity of halophilic yeast-like melanized fungi. Extremophiles 8, 53-61. doi: 10.1007/s00792-003-0360-5

van der Werf, M. J., Overkamp, K. M., Muilwijk, B., Coulier, L., and Hankemeier, T. (2007). Microbial metabolomics: toward a platform with full metabolome coverage. Anal. Biochem. 370, 17-25. doi: 10.1016/j.ab.2007.07.022

Vance, J. E., and Steenbergen, R. (2005). Metabolism and functions of phosphatidylserine. Prog. Lipid Res. 44, 207-234. doi: 10.1016/ j.plipres.2005.05.001

Ventosa, A., Nieto, J. J., and Oren, A. (1998). Biology of moderately halophilic aerobic bacteria. Microbiol. Mol. Biol. Rev. 62, 504-544.

Villas-Boas, S. G. (2016). "Introduction to microbial metabolomics", in Microbial Metabolomics, eds D. Beale, K. Kouremenos, and E. Palombo (Cham: Springer), $1-12$.

Vreeland, R. H., Piselli, A. F. Jr., McDonnough, S., and Meyers, S. S. (1998). Distribution and diversity of halophilic bacteria in a subsurface salt formation. Extremophiles 2, 321-331. doi: 10.1007/s007920050075

Wishart, D. S., Jewison, T., Guo, A. C., Wilson, M., Knox, C., Liu, Y., et al. (2013). HMDB 3.0-the human metabolome database in 2013. Nucleic Acids Res. 41, D801-D807. doi: 10.1093/nar/gks1065

Xiang, W., Guo, J., Feng, W., Huang, M., Chen, H., Zhao, J., et al. (2008). Community of extremely halophilc bacteria in historic Dagong Brine well in southwestern China. World J. Microbiol. Biotechnol. 24, 2297-2305. doi: 10.1007/s11274-008-9744-0

Xu, Y.-J., Wanga, C., Ho, W. E., and Ong, C. N. (2014). Recent developments and applications of metabolomics in microbiological investigations. Trends Analyt. Chem. 55, 37-48. doi: 10.1016/j.trac.2013.12.009

Yadav, A. N., Sharma, D., Gulati, S., Singh, S., Dey, R., Pal, K. K., et al. (2015). Haloarchaea endowed with phosphorus solubilization attribute implicated in phosphorus cycle. Sci. Rep. 5:12293. doi: 10.1038/srep 12293

Zhang, C., Zhang, D., and Cheng, J. X. (2015). Coherent raman scattering microscopy in biology and medicine. Annu. Rev. Biomed. Eng. 17, 415-445. doi: 10.1146/annurev-bioeng-071114-040554

Conflict of Interest Statement: The authors declare that the research was conducted in the absence of any commercial or financial relationships that could be construed as a potential conflict of interest.

The reviewer TC and handling Editor declared their shared affiliation.

Copyright (C) 2017 Adamiak, Bonifay, Otlewska, Sunner, Beech, Stryszewska, Kańka, Oracz, Żyzelewicz and Gutarowska. This is an open-access article distributed under the terms of the Creative Commons Attribution License (CC BY). The use, distribution or reproduction in other forums is permitted, provided the original author(s) or licensor are credited and that the original publication in this journal is cited, in accordance with accepted academic practice. No use, distribution or reproduction is permitted which does not comply with these terms. 